\title{
Innovative methods of providing food security of the penitentiary system
}

\author{
Irina Firsova ${ }^{1}$, Galina Pyrchenkova ${ }^{2}$, and Elena Radchenko ${ }^{1^{*}}$ \\ ${ }^{1}$ Academy of Management of the Ministry of Internal Affairs of Russia, 8 Kosmodemyansky Street, \\ Moscow, 125171, Russia \\ ${ }^{2}$ Federal State Research Institute of the Federal Penitentiary Service of the Russian Federation, 15 A \\ Narvskaya Atreet, Moscow, 125130, Russia
}

\begin{abstract}
The objective need to reduce the budget expenditures on food for persons held in correctional institutions forces us to find ways to use the available resources more effectively. When dealing with food provision issues, it is necessary to keep in mind food security, that is, the stability of supplies and the availability of stocks in the required volume. Increasing the level of self-sufficiency in food in the penitentiary system of the Russian Federation with the simultaneous optimization of production costs for manufactured products looks like an obvious way to reduce budget expenditures. In the authors' opinion the presence of own agricultural producers (correctional institutions, as well as their subsidiary farms, federal state unitary enterprises engaged in agricultural activities) makes it possible to manufacture products with a minimum cost close to the production cost. In this aspect, it becomes very important to improve the organization of production processes through the use of software products. The article considers the advantages of using information and communication technologies in crop production and defines ways to optimize costs and reduce budget expenditures on food provision for convicts.
\end{abstract}

\section{Introduction}

Currently, one of the main tasks of the penitentiary system of the Russian Federation is to provide persons in prisons with food of its own production [1, 2]. The first and the fundamental branch of agricultural production in the Russian penitentiary system is crop production. The development of crop production and an increase in its productivity with the use of modern technologies is one of the methods of ensuring food security of the penitentiary system [3]. This goal can be achieved by:

- the consistent introduction of adaptive landscape farming to replace the existing systems of land use;

- the use of energy and resource saving technologies, for example, taking advantage of zero (No-Till) or minimal land cultivation systems.

\footnotetext{
* Corresponding author: helenr2003@mail.ru
} 
The scientific basis of agricultural production is agronomy - a complex of agronomic science and practical techniques for cultivating agricultural crops, increasing soil fertility and land use efficiency. Agronomy is based on such sciences as general agriculture, soil science, agrochemistry, agrophysics, crop production, selection and seed production, entomology, land reclamation, and others.

The production of agricultural crops without appropriate knowledge can lead not only to a decrease in yield, but also to its complete loss and the inability to use agricultural land. Specialists engaged in the cultivation of agricultural crops in the penitentiary system should know the basics of agronomy as a science of agriculture. They should be able to develop agrotechnical techniques for obtaining high yields and reducing the cost of production. The Federal State Research Institute of the Federal Penitentiary Service of the Russian Federation has conducted a survey on the development of the automated information system "Crop Production in the Penitentiary System" (further - the automated system) designed to form process maps for the cultivation and harvesting of crops, which allow to plan costs, agricultural practices and their timing, use of tractor fleet in the penitentiary system.

All of the above points to the need to introduce innovative programs in the crop production of the penitentiary system, transition to advanced technologies and new forms of agricultural production, and accelerated approach to world achievements in this area.

The issues of state support and regulation of the agro-industrial complex and its interaction with the agricultural business are given sufficient attention in the works of the leading domestic scientists [4-12]. The issues of innovative methods of crop production have also been the subject of investigation of a number of foreign scientists [13-18].

Nevertheless, the generalization of the results of the research showed that these issues have not yet been sufficiently studied. The unsolved problems include the scientific substantiation of the use of automated system, for example, for soil analysis, not only in the agricultural sector of the penitentiary system, but also in the agro-industrial complex as a whole. In this study, the use of automated system in crop production will be considered as an activity aimed at achieving increased yields within the framework of ensuring food security of the penitentiary system.

\section{Research methods}

Modern technologies for the production of crop products imply a clear implementation of all operations of the technological chain related to soil preparation for planting various crops, methods of sowing seeds, the use of fertilizers and plant protection products, harvesting, transportation, storage of crops, and so on [5].

From the point of view of management accounting, any technological operation is aimed at obtaining high, pre-calculated crop yields that meet certain agronomic requirements, taking into account the minimization of losses and the optimization of production costs.

The complication of agro-technological operations in crop production of the penitentiary system together with an increase in their diversity determines the need for scientific research in such an urgent area as digitalization in agriculture. With the help of the automated system developed for crop production in the penitentiary system, it becomes easier to process the incoming information flows in computers.

Let's consider the procedure for the formation of agricultural products in the given conditions using a specialized program. 
The consistent implementation of various types of agro-technological operations by the manufacturers of the penitentiary system require the use of effective machine-tractor units, taking into account the climatic, soil and production characteristics. The complex of agricultural activities should be interconnected: the previous operation should be the basis for the subsequent one.

The assembly of units is carried out not only depending on their technical characteristics, but also on the capabilities of agricultural producers of the penitentiary system. When choosing machines and the required units (arable, harrow and others), preference is given to the most productive, serviceable, easy to maintain, capable of performing work efficiently on time and at minimal cost units.

However, the lack of sufficient agricultural machinery and limited investment opportunities lead to the planning of agricultural technology operations only after an objective assessment of the alternative attracting a third-party contractor for the purpose of efficient and rational manufacturing of products. That is, the choice of the executive of the operation aimed at reducing the cost of the product is as important as the definition of the method of its implementation, the selection of agricultural machinery. Depending on the needs of the penitentiary system units, various services of the third-party organizations can be applied in any agrotechnological operation. The search for the most effective option for performing an agricultural operation is carried out at the lowest cost of its execution, subject to the conditions of quality and timeliness.

The cultivation of any agricultural crops is based on a set of interrelated agrotechnological operations, which, in turn, are drawn up in a document that combines the entire production process into one whole - a technological map.

The automated system is directly designed for the formation of technological maps for the cultivation and harvesting of agricultural crops in the penitentiary system, and serves, as a rule, as a supplement to existing software products created in such large systems as budget and financial management. In the automated system, a document is created in the form of a draft technological map, which in a certain sequence reflects the agricultural operations (types of work) included in the technological process, their technical and economic characteristics, timing, as well as the planned cost of the final crop product.

For the convenience of calculations, the draft technological map is made for a conditional area (10 ha, 100 ha, etc.) or for the entire planned area of sowing (planting) of a crop or group of crops that are homogeneous in cultivation technology [6].

For each added agricultural operation, the user who forms the technological map must set the time limit for field and stationary work. The approximate agrotechnical terms of performance of individual field works are presented in Table 1. [6]. 
Table 1. Approximate agrotechnical deadlines for field work for the Central Federal District.

\begin{tabular}{|c|c|c|}
\hline 1. & Spring closing of moisture by harrowing & $2-3$ days \\
\hline 2. & Sowing of grain (ear) crops & $4-5$ days \\
\hline 3. & Planting potatoes & $7-8$ days \\
\hline 4. & Row-to-row processing in one direction & $4-5$ days \\
\hline 5. & Chemical weeding & $4-5$ days \\
\hline 6. & Cultivation of finch & $4-5$ days \\
\hline 7. & Pre-sowing cultivation & $2-3$ days \\
\hline 8. & Rolling up crops & $4-5$ days \\
\hline 9. & Application of mineral fertilizers & 3 days \\
\hline 10. & Plowing the swell & 10 days \\
\hline 11. & Grain harvesting & $8-10$ days \\
\hline 12. & Potato harvesting & $12-15$ days \\
\hline 13. & Stubble peeling & $8-10$ days \\
\hline 14. & & 10 days \\
\hline
\end{tabular}

Filling in the technological map is carried out for a specific agricultural division of the penitentiary system by entering information in it in the form of separate indicators, such as:

$\checkmark \quad$ cultivated crop, variety, hybrid;

$\checkmark \quad$ seeding area;

$\checkmark \quad$ predecessor;

$\checkmark \quad$ planned yield;

$\checkmark \quad$ the seeding rate;

$\checkmark \quad$ the rate of fertilizer application;

$\checkmark \quad$ the rate of consumption of toxic chemicals;

$\checkmark \quad$ distance to the field;

$\checkmark \quad$ duration of the work shift;

$\checkmark \quad$ fuel and lubricants consumption;

$\checkmark \quad$ electricity for technological purposes;

$\checkmark \quad$ transportation costs;

$\checkmark \quad$ wages and others.

The values of the indicators are entered into the corresponding columns of the draft technological map, after which the list and sequence of the main agro-technological operations for the cultivation of agricultural crops are determined. The sequence of operations is put down line by line in the tabular part of the project flow chart in accordance with the planned timing of their implementation and the recommended unit. 
The development of agro-technological operations is carried out on the basis of knowledge about the technology of cultivation of an agricultural crop, taking into account the need for seeds and planting material, fertilizers and plant protection products, and, ultimately, methods of harvesting in the penitentiary system. Soil and climatic conditions of the region, the agricultural crop (or fallow) that occupied the field in the previous year, soil fertility, mineral and organic fertilizers previously used by agronomists, and pesticides should also be considered.

When planning costs and reflecting them in the draft technological map, in addition to direct costs, indirect costs, such as general production, general economic and other expenses, are provided for. As a simplification of entering information about overhead costs, their size is set as a percentage of the amount of direct costs for each agrotechnological operation.

The automated system already contains reference books with up-to-date information on the most common agricultural operations and agricultural machinery. The user can change or add records of the current directory, based on the actual household technology cultivation methods, application of fertilizers and pesticides, harvesting, available units of agricultural machinery park, material and technical resources, etc. When forming a technological operation, the established and approved rate of production of the unit or agricultural machine should be taken into account. If several works (as part of an agricultural operation) are performed in a complex by the same mechanisms, but they have different production standards, then such works are divided into separate directory entries. For example, loading and delivery of fertilizers as part of the unit: tractor with an installed front loader in a hitch with a trailer has different production standards for loading and for transportation, that is, two agricultural operations are recorded.

By concentrating information on all the costs associated with the cultivation and harvesting of agricultural crops in the penitentiary system in a single automated system, there is a real opportunity to calculate the cost of the final product. The availability of data on the optimal variant of the formation of a particular agricultural operation and / or a group of such operations, which are part of the technological process, makes it possible to effectively use the cost management system, to reliably determine the pricing policy for manufactured products.

\section{Results}

The automated system is developed on the $1 \mathrm{C}$ platform: Enterprise. Its introduction into a personal computer involves the installation of the software product "1C Enterprise 8 " on the basis of one of the operating systems:

- $\quad$ Microsoft Windows XP Service Pack 3 and higher;

- $\quad$ Linux Linux (Alt Linux SPT 6.0, Mint 12, Fedora 17, Ubuntu 12.04 LTS (Precise Pangolin), Astra Linux Special Edition 1.4 and higher);

- MacOSX 10.8 and higher.

The developed automated system in the agricultural sector of the penitentiary system is designed for planning a complex of agricultural techniques for growing crops, calculating and then analyzing the composition and structure of costs for individual agricultural operations and in general, forecasting the cost of crop production.

The advantages of implementing an automated system are:

- ability of the penal manufacturer to automatically generate a technological map with flexible configuration for the specifics of the region; 
- unification and standardization of agronomic activities in the penitentiary system, introduction of a unified approach to solving problems in crop production;

- building of an effective management accounting system;

- reducing the workload placed on specialists;

- use of generalized information about available agricultural machinery in the penitentiary system and planning of technological operations depending on the availability of the machine and tractor fleet;

- $\quad$ use of the program reference books with up-to-date information about the machine and tractor fleet of the Russian and foreign production, indicating actual technical and economic characteristics (brand of agricultural machinery, book value, unit performance, fuel and lubricants consumption rates, maintenance and repair costs, depreciation rates, the number of performers required for uninterrupted maintenance of the unit, etc.);

- planning the technology of cultivation of agricultural crops, based on the choice of different sequences of agrotechnological operations;

- calculation of costs for a single agricultural operation or for the entire technological process, depending on the tractors, combines, mounted and trailed machines and tools used;

- determining the expediency of attracting third-party performers for the most effective option for performing an agricultural operation at the lowest price, while meeting the conditions of quality and timeliness.

- visual representation of the results of comparing several options of process maps for optimal selection;

- $\quad$ planning plant protection measures to eliminate or reduce crop losses caused by pests, plant diseases and weeds;

- comparison of costs for the corresponding terms of agricultural machinery with the cash flow plan;

- $\quad$ as an alternative - updating the database of statistical reports of the penitentiary system with information on individual indicators in order to identify advanced farms and analyze the results of agricultural activities in the penitentiary system;

- reducing the number of violations of law as a result of using the automating the process (especially due to the absence or presence of low-skilled professionals).

\section{Conclusions}

At the initial stage of the implementation of the automated system in the activities of the penitentiary system the following results were obtained:

- the essence of information support as an element of influence on controlled objects was disclosed;

- the procedure for the formation of a system of on-farm planning in crop production was investigated;

- $\quad$ the specific features of modeling information processes were revealed;

- the information technologies tools for planning crop production were tested.

According to the authors, the presence of own agricultural producers allows the penitentiary system to manufacture products with a minimum cost, close to the production cost. In this regard, it is very important to improve the organization of production processes by using a software product that enables a specialist to correctly make a decision on the effective use of financial and material resources in agricultural production. 
The use of the automated system in crop production contributes to an increase in the level of self-sufficiency in food in the penitentiary system, while optimizing production costs for manufactured products, which helps to reduce budget expenditures and production risks.

\section{References}

1. Food and Agriculture Organization of the United Nations [Electronic resource] http://www.fao.org/statistics/ru/ (date of access: 20.01.2021).

2. M. Kozin, G. Pyrchenkova, E. Radchenko, E3S Web of Conferences, 135, 01101 (2019), doi:10.1051/e3sconf/201913501101.

3. Zh.N. Dibrova, V.V. Nosov, G.S. Ovchenkova, et al., International Journal of Mechanical Engineering and Technology, 9(13), 387-394 (2018)

4. V.V. Nosov, M.N. Kozin, V.I. Andreev, et al., Research Journal of Pharmaceutical, Biological and Chemical Sciences, 7(6), 382-385 (2016)

5. K.A. Zhichkin, V.V. Nosov, V.I. Andreev, et al., Damage modelling against nontargeted use of agricultural lands, in Proceedings of the conference AgroCON-2019 (2019)

6. V.V Nosov, M.N. Kozin, T.N. Gladun, Ecology, Environment and Conservation, 21, AS103-AS110 (2015)

7. V.V Nosov, O. Moiseeva, N.P. Kiseleva, et al., International Journal of Recent Technology and Engineering, 8(4), 3638-3644 (2019)

8. M.T. Tekueva, A.V. Burkov, V.V. Nosov, et al., Research Journal of Pharmaceutical, Biological and Chemical Sciences, 7(6), 1634-1638 (2016)

9. Zh.A. Zakharova, P.N. Zakharov, Problems of Territorial Development, 2(94), 47-56 (2018), doi: 10.15838 / ptd / 2018.2.94.3.

10. V.A. Sedykh, E. P. Radchenko, Y. Y. Tishchenko, G. S. Pyrchenkova, IOP Conference Series: Earth and Environmental Science, 548 (8), 082031 (2020), ISSN: 1755131517551307

11. V. Sedykh, G. Pyrchenkova, E. Radchenko, IOP Conf. Series: Earth and Environmental Science, 548, 082031 (2020), doi:10.1088/1755-1315/548/8/082031

12. V. A. Sedykh, A. V. Rodionov, News of the Criminal Executive System, 11 (186), 35 41 (2017)

13. M. Rankin, E. Nogales, P. Santacoloma, N. Mhlanga, C. Rizzo, Public-private partnerships for agribusiness development. A review of international experiences (Rome, Italy, 2016)

14. F. Geerling-Eiff, J. Potters, L. Klerkx, NJAS - Wageningen Journal of Life Sciences, 88, 76 (2019), https://doi.org/10.1016/j.njas.2018.10.001

15. L. Demmou, A. Wörgötter, OECD Economics Department Working Papers, 1189 (2015), http://dx.doi.org/10.1787/5js4w26114r2-en

16. T. A. Delbridge, C. Fernholz, R. P. King, W. Lazarus, Agric. Syst., 122, 1-10 (2013), https://doi.org/10.1016/j.agsy.2013.07.007.

17. A. Früh-Müller, C. Krippes, S. Hotes, et al., Ecol. Indic., 84, 364-370 (2018), https://doi.org/10.1016/j.ecolind.2017.09.008 
18. H. Lu, H. Xie, Y. He, et al., Agric. Syst., 161, 81-88 (2018), https://doi.org/10.1016/j. agsy.2018.01.001. 